Discussion Paper No. 770

\title{
HOW DO MARKET STRUCTURES AFFECT DECISIONS ON VERTICAL INTEGRATION/SEPARATION?
}

\author{
Noriaki Matsushima \\ Tomomichi Mizuno
}

February 2010

The Institute of Social and Economic Research

Osaka University

6-1 Mihogaoka, Ibaraki, Osaka 567-0047, Japan 


\title{
How do market structures affect decisions on vertical integration/separation?*
}

\author{
Noriaki Matsushima ${ }^{\dagger}$ \\ Institute of Social and Economic Research, Osaka University \\ Tomomichi Mizuno \\ Competition Policy Research Center, Japan Fair Trade Commission
}

January 31, 2010

\begin{abstract}
We provide a simple model to investigate decisions on vertical integration/separation. The key feature of this model is that more than one input is required for the final products of the local downstream monopolists. Depending on their cost structure, downstream firms' decisions on vertical separation can be both strategic complements and strategic substitutes. As a result, the equilibrium number of vertically integrated firms depends on the cost structure. When the local downstream monopolists merge, vertical separation tends to appear in equilibrium. When an upstream firm can price discriminate, the downstream firms vertically separate. When the downstream firms compete with each other, vertical integration tends to appear if the degree of product differentiation is lower.
\end{abstract}

JEL Classification Codes: D43, L13, L22, M11.

Key Words: vertical integration, vertical separation, local monopolists, inputs, technology.

*The first author gratefully acknowledges financial support from the Ministry of Education, Science, Sports and Culture, Grant-in-Aid for Scientific Research (C) (21530243) and Young Scientists (B) (21730193). Of course, any errors are the responsibility of the authors. The views expressed herein are those of the authors and should not be interpreted as those of the Japan Fair Trade Commission.

${ }^{\dagger}$ Corresponding author: Noriaki Matsushima, Institute of Social and Economic Research, Osaka University, Mihogaoka 6-1, Ibaraki, Osaka 567-0047, Japan. Phone: +81-6-6879-8571. E-mail: nmatsush@iser.osaka-u.ac.jp 


\section{Introduction}

Determinants of vertical structure have long been discussed in the management and economics literature. ${ }^{1}$ Investigating this problem is difficult because there can be many determinants of vertical structure. The following reflects the difficulty of this problem. The extent of vertical specialization varies considerably among countries and industries (Hummels et al. (1998)). For instance, in the apparel industry, some brands (The Gap, L.L. Bean, and Eddie Bauer) are distributed through vertically integrated specialized retailers. Others (Tommy Hilfiger and Calvin Klein) are distributed primarily on a nonexclusive basis through department stores and other nonintegrated retailers (Gertner and Stillman (2001)). In the assembly industries, companies in Western European countries are less integrated than those in the US, but they are still far more integrated than those in Japan. There are also significant differences in vertical industry structure among individual European economies (Hemmert (1999)). We therefore think that providing an analytic framework to investigate this problem is important from the viewpoints of management and economics.

We provide a simple model to investigate decisions about vertical separation (integration) and show several results that have not been explained in previous research (we mention the difference between this model and those in related previous studies below). The key feature of this model is that more than one input is required for the final products of the local downstream monopolists. ${ }^{2}$ The model can be applied to many industries. For instance, in the aircraft industry, two major firms, Airbus and Boeing, rely heavily on firm-specific inputs (e.g., engines, wings, horizontal stabilizers) produced by independent

\footnotetext{
${ }^{1}$ Macher and Mowery (2004) clearly summarize the research on the relation between vertical specialization and industry structure.

2 This setting is related to models with complementary suppliers (Economides and Salop (1992), Nalebuff (2000), Baldwin and Woodard (2007), Casadesus-Masanell et al. (2007), and Maruyama and Minamikawa (2009)). These papers discuss how mergers among complementary suppliers appear and/or how these mergers change equilibrium outcomes. Such complementary suppliers provide their products directly to consumers. This setting is quite different from ours. Note that the meaning of the term 'vertical integration' in these papers is different from that in our paper. Although a merger among complementary suppliers is called 'vertical integration' in these papers, in our model the term indicates a merger between an upstream and a downstream firm.
} 
manufacturers, and then sell their aircraft to airline companies, which are the final customers (Beelaerts van Blokland et al. (2008)).

The model structure is as follows. There are two independent local downstream monopolists $D_{1}$ and $D_{2}$ that use two inputs: $A$, and either $B_{1}$ or $B_{2} \cdot{ }^{3}$ The inputs are produced by an independent upstream supplier $A$ and a production unit inside the downstream firm $D_{i}(i=1,2)$. The nondiscriminatory wholesale price of input $A$ is unilaterally determined by supplier $A{ }^{4}$ To produce a final product, $D_{i}$ needs $c_{i}$ units of input $A$, and one unit of input $B(i=1,2) . D_{1}$ is more efficient than $D_{2}$, that is, $c_{2}>c_{1}$. In this model, $c_{2} / c_{1}$ represents the efficiency difference between the downstream firms. Under this condition, we consider four cases: (1) both downstream firms produce units of input $B,(2)$ both downstream firms separate from their input production units, and $(3,4)$ one of the downstream firms separates from its input production unit. The separated unit (supplier $B_{i}$ ) supplies to the downstream firm $D_{i}$ to maximize its own profit $(i=1,2) .^{5}$

[Figure 1 here]

We show that depending on the production technologies of the downstream firms $\left(c_{2} / c_{1}\right)$, the following three situations concerning the vertical structures of the downstream firms appear: both downstream firms vertically integrate or neither do when $c_{2} / c_{1}$ is small; only the efficient downstream firm vertically integrates when $c_{2} / c_{1}$ is large. In this model, depending on the efficiency difference, decisions on vertical integration can be both strategic complements and strategic substitutes.

This result is related to Buehler and Schmutzler (2005), who examine the reasons that asymmetric vertical structures are established and that integrated firms tend to be large in many industries. ${ }^{6}$ Using a reduced-form successive Cournot model (see Salinger (1988)), they show the two following results:

\footnotetext{
3 To discuss decisions of vertical integration, Laussel (2008) and Matsushima and Mizuno (2009) provide models with multiple inputs. In these two papers, there is only one downstream firm that determines its vertical structure.

4 In Section 5, we briefly discuss price discrimination by suppler $A$.

${ }^{5}$ We assume that the downstream firm cannot merge with supplier $A$. A more detailed discussion of the assumption is provided in Section 2.

6 Buehler and Schmutzler (2005) provide several examples related to asymmetric vertical structures.
} 
(1) there may be asymmetric equilibria where only one of the symmetric firms vertically integrates; and

(2) efficient firms are more likely to integrate when downstream firms differ with respect to their initial efficiency levels. ${ }^{7}$ The latter result suggests that large firms are more likely to integrate vertically. ${ }^{8}$

Our paper contributes to the literature on vertical integration. First, we provide a market structure with the following feature: depending on the cost structure of downstream firms, the downstream firms' decisions on vertical separation can be both strategic complements and strategic substitutes, whereas vertical integration decisions of downstream firms in Buehler and Schmutzler (2005) are strategic substitutes. As a result, one of our models can derive the following three situations concerning the vertical structures of the downstream firms: both downstream firms vertically integrate and no downstream firm vertically integrates when the decisions on vertical integration are strategic complements; only one downstream firm vertically integrates when the decisions on vertical integration are strategic substitutes. ${ }^{9}$ Second, our model shows that downstream competition in itself is not essential in decisions of vertical integration/separation. In our model, the two downstream firms are local monopolists and procure their inputs from a common supplier. ${ }^{10}$ This feature of our model is quite different from those of the previous studies.

We extend the basic model in several directions. First, we consider a downstream merger. When the downstream firms merge, full integration does not appear in equilibrium but rather vertical separation tends to do so. This tendency reduces social welfare. This property can explain why merged firms tend to spin off their previously integrated supplier divisions. For instance, in the late 1990s, Mercedes Benz and Chrysler merged and then restructured their supplier relations around a minimum number of

\footnotetext{
7 Linnemer (2003) and Dufeu (2004) also discuss vertical integration under Cournot competition.

8 Several papers also derive asymmetric equilibria related to vertical integration. See Ordover et al. (1990), Gaudet and Long (1996), Abiru et al. (1998), Choi and Yi (2000), Church and Gandal (2000), Chen (2001), Elberfeld (2002), Jensen (2003), and Matsushima (2004, 2009).

${ }^{9}$ Using a Hotelling linear city model, Matsushima (2009) also shows these three vertical structures, which are affected by exogenous parameters. The mechanism used to derive those results is quite different from ours. In Matsushima (2009), vertical integration affects the locations of downstream firms in the Hotelling linear city, and the locations affect decisions on vertical integration.

10 In Section 6, we briefly discuss the strategic interaction between the downstream firms.
} 
full-service-development and logistics partners (Olin et al. (1999)). To our knowledge, in the literature of industrial organization, the relation between a downstream merger and vertical structure has not been discussed (we briefly mention this in Section 4).

Second, we allow supplier $A$ to price discriminate. This is related to the literature of input price discrimination (De Graba (1990), Yoshida (2000), Inderst and Valletti (2009)). We show that both downstream firms vertically separate when supplier $A$ price discriminates. As a result, allowing price discrimination reduces social welfare. Third, we investigate the case in which the downstream firms compete. We show that the downstream firms tend to integrate when the degree of product differentiation is lower.

The remainder of this paper is organized as follows. Section 2 formulates the model. Section 3 presents the results. Sections 4, 5, and 6 extend the basic model. Section 4 discusses the case of downstream merger. Section 5 discusses the case of input price discrimination. Section 6 introduces downstream market competition into the basic model. Section 7 concludes the paper.

\section{The model}

Consider two independent downstream markets. In each market, there is a downstream firm that uses two inputs, $A$ and $B$. The two inputs are produced by a common upstream supplier $A$ and a production unit within each downstream firm $i(i=1,2)$. We call the internal production unit $B i(i=1,2)$. To simplify the analysis, we assume that the common wholesale price of input $A$ is unilaterally determined by the supplier. In each market, the demand for the product is linear:

$$
p_{i}=1-Q_{i},
$$

where $p_{i}$ is the market price, and $Q_{i}$ is the output supplied by the downstream firm $D_{i}(i=1,2)$.

An initial simplifying assumption is that the downstream firms are located in separate geographic markets. Thus, the downstream firms compete for inputs from upstream supplier $A$, and upstream suppliers indirectly compete to supply them but downstream firms do not compete directly with one 
another. This assumption clarifies the mechanism behind the main results. Thus, having built intuition and analysis based on an independent final good market assumption, we will (in Section 4) amend our analysis to include head-to-head competition between downstream firms.

We consider two cases concerning production technologies. (i) Downstream firm $i$ produces a unit of final product using $c_{i}$ units of input $A$ and one unit of input $B i$. (ii) Downstream firm $i$ produces a unit of final product using one unit of input $A$ and $c_{i}$ units of input $B i$. Hence, each production technology is denoted by:

$$
\begin{aligned}
\text { case (i): } Q_{i}=\min \left\{q_{A} / c_{i}, q_{B i}\right\}, \\
\text { case (ii): } Q_{i}=\min \left\{q_{A}, q_{B i} / c_{i}\right\},
\end{aligned}
$$

where $q_{i}$ is the amount of input $j\left(j=A, B_{i}\right)$ and $c_{i}$ is a positive constant $(i=1,2)$. Each downstream firm uses Leontief production technology. No firm incurs an additional marginal cost for a unit of product except for the input prices set by the suppliers. Per unit production cost of $D_{i}\left(w_{i}, i=1,2\right)$ is written by $\left(w_{B i}=0\right.$ if $D_{i}$ and $B i$ are not separated $)$

$$
\begin{aligned}
& \text { case (i): } w_{i}=c_{i} w_{A}+w_{B i}, \\
& \text { case (ii): } w_{i}=w_{A}+c_{i} w_{B i} .
\end{aligned}
$$

To discuss the decisions on vertical separation, we must consider the following three cases: (1) both downstream firms separate from their respective input production units (full separation), (2) only one downstream firm separates (partial separation), and (3) no downstream firm separates (no separation).

We assume that the downstream firm cannot merge with firm $A$. We now explain why the downstream firm cannot merge with firm $A$. In general, downstream firms compete, and usually procure their inputs from common suppliers (Ahmadjian and Lincoln (2001)). In this situation, a vertical merger between firm $A$ and a downstream firm tends to be prohibited by antitrust authorities because of the foreclosure problem (Rey and Tirole (2007)). Although the two markets are independent in our model, our setting is also applicable to the case in which two markets are interdependent and represented by 
standard differentiated inverse demand functions $p_{i}=1-Q_{i}-\gamma Q_{j}(i=1,2, i \neq j)$. Therefore, this assumption is plausible.

To develop an equilibrium theory of vertical integration, I follow the method of Pepall et al. (2004, p. 439) and analyze a stage game. The game runs as follows. First, each downstream firm determines whether to separate from its input unit. Second, given the decisions of the downstream firms, the supplier(s) determine the wholesale price(s). Third, given the wholesale price(s), each downstream firm sets the quantity it supplies.

\section{$3 \quad$ Results}

We now calculate two cases concerning production technologies.

\subsection{Case (i): $Q_{i}=\min \left\{q_{A} / c_{i}, q_{B i}\right\}$}

Given the wholesale prices $w_{A}, w_{B 1}$, and $w_{B 2}$, the maximization problem of $D_{i}$ is:

$$
\max _{Q_{i}}\left(1-Q_{i}-c_{i} w_{A}-w_{B i}\right) Q_{i}
$$

The first-order conditions lead to:

$$
Q_{i}=\frac{1-c_{i} w_{A}-w_{B i}}{2}, \quad \pi_{D_{i}}=\frac{\left(1-c_{i} w_{A}-w_{B i}\right)^{2}}{4}
$$

As mentioned earlier, the wholesale prices are unilaterally determined by the suppliers. The maximization problems of suppliers $A$ and $B_{i}$ are:

$$
\begin{aligned}
& \max _{w_{A}} w_{A}\left(c_{1} Q_{1}+c_{2} Q_{2}\right) \Rightarrow \max _{w_{A}} w_{A} \sum_{i=1}^{2} c_{i} \frac{1-c_{i} w_{A}-w_{B i}}{2}, \\
& \max _{w_{B i}} w_{B i} \frac{1-c_{i} w_{A}-w_{B i}}{2},(i=1,2) .
\end{aligned}
$$

Here we have three cases of vertical structure: (1) full separation, (2) partial separation, and (3) no separation. Taking into account that $w_{B i}=0$ if firm $i$ does not separate from $B i$, we derive the 
first-order condition(s) of the supplier(s). These condition(s) lead to:

$$
\begin{aligned}
\text { (1) } w_{A}^{S S} & =\frac{c_{1}+c_{2}}{3\left(c_{1}^{2}+c_{2}^{2}\right)}, \quad w_{B i}^{S S}=\frac{2 c_{i}^{2}-c_{i} c_{j}+3 c_{j}^{2}}{6\left(c_{1}^{2}+c_{2}^{2}\right)}, \\
\pi_{D i}^{S S} & =\frac{\left(2 c_{i}^{2}-c_{i} c_{j}+3 c_{j}^{2}\right)^{2}}{144\left(c_{1}^{2}+c_{2}^{2}\right)^{2}}, \quad \pi_{B i}^{S S}=\frac{\left(2 c_{i}^{2}-c_{i} c_{j}+3 c_{j}^{2}\right)^{2}}{72\left(c_{1}^{2}+c_{2}^{2}\right)^{2}}, \\
(2 a) \quad w_{A}^{S I} & =\frac{c_{1}+2 c_{2}}{3 c_{1}^{2}+4 c_{2}^{2}}, \quad w_{B 1}^{S I}=\frac{c_{1}^{2}-c_{1} c_{2}+2 c_{2}^{2}}{3 c_{1}^{2}+4 c_{2}^{2}}, \\
\pi_{D 1}^{S I} & =\frac{\left(c_{1}^{2}-c_{1} c_{2}+2 c_{2}^{2}\right)^{2}}{4\left(3 c_{1}^{2}+4 c_{2}^{2}\right)^{2}}, \quad \pi_{B 1}^{S I}=\frac{\left(c_{1}^{2}-c_{1} c_{2}+2 c_{2}^{2}\right)^{2}}{2\left(3 c_{1}^{2}+4 c_{2}^{2}\right)^{2}}, \quad \pi_{D 2}^{S I}=\frac{\left(3 c_{1}^{2}-c_{1} c_{2}+2 c_{2}^{2}\right)^{2}}{4\left(3 c_{1}^{2}+4 c_{2}^{2}\right)^{2}} \\
(2 b) \quad w_{A}^{I S} & =\frac{2 c_{1}+c_{2}}{4 c_{1}^{2}+3 c_{2}^{2}}, \quad w_{B 2}^{I S}=\frac{2 c_{1}^{2}-c_{1} c_{2}+c_{2}^{2}}{4 c_{1}^{2}+3 c_{2}^{2}}, \\
\pi_{D 1}^{I S} & =\frac{\left(2 c_{1}^{2}-c_{1} c_{2}+3 c_{2}^{2}\right)^{2}}{4\left(4 c_{1}^{2}+3 c_{2}^{2}\right)^{2}}, \quad \pi_{D 2}^{I S}=\frac{\left(2 c_{1}^{2}-c_{1} c_{2}+c_{2}^{2}\right)^{2}}{4\left(4 c_{1}^{2}+3 c_{2}^{2}\right)^{2}}, \quad \pi_{B 2}^{I S}=\frac{\left(2 c_{1}^{2}-c_{1} c_{2}+c_{2}^{2}\right)^{2}}{2\left(4 c_{1}^{2}+3 c_{2}^{2}\right)^{2}} \\
\text { (3) } \quad w_{A}^{I I} & =\frac{c_{1}+c_{2}}{2\left(c_{1}^{2}+c_{2}^{2}\right)}, \quad \pi_{D 1}^{I I}=\frac{\left(c_{1}^{2}-c_{1} c_{2}+2 c_{2}^{2}\right)^{2}}{16\left(c_{1}^{2}+c_{2}^{2}\right)^{2}}, \quad \pi_{D 2}^{I I}=\frac{\left(2 c_{1}^{2}-c_{1} c_{2}+c_{2}^{2}\right)^{2}}{16\left(c_{1}^{2}+c_{2}^{2}\right)^{2}},
\end{aligned}
$$

where the superscript $S S$ denotes the full-separation setting; the superscript $S I$ (resp. $I S$ ) denotes that $D_{1}\left(\right.$ resp. $\left.D_{2}\right)$ separates and $D_{2}\left(\right.$ resp. $\left.D_{1}\right)$ integrates; the superscript $I I$ denotes the no-separation setting.

From the above results, we can make the following payoff matrix related to the first-stage decisions of the downstream firms.

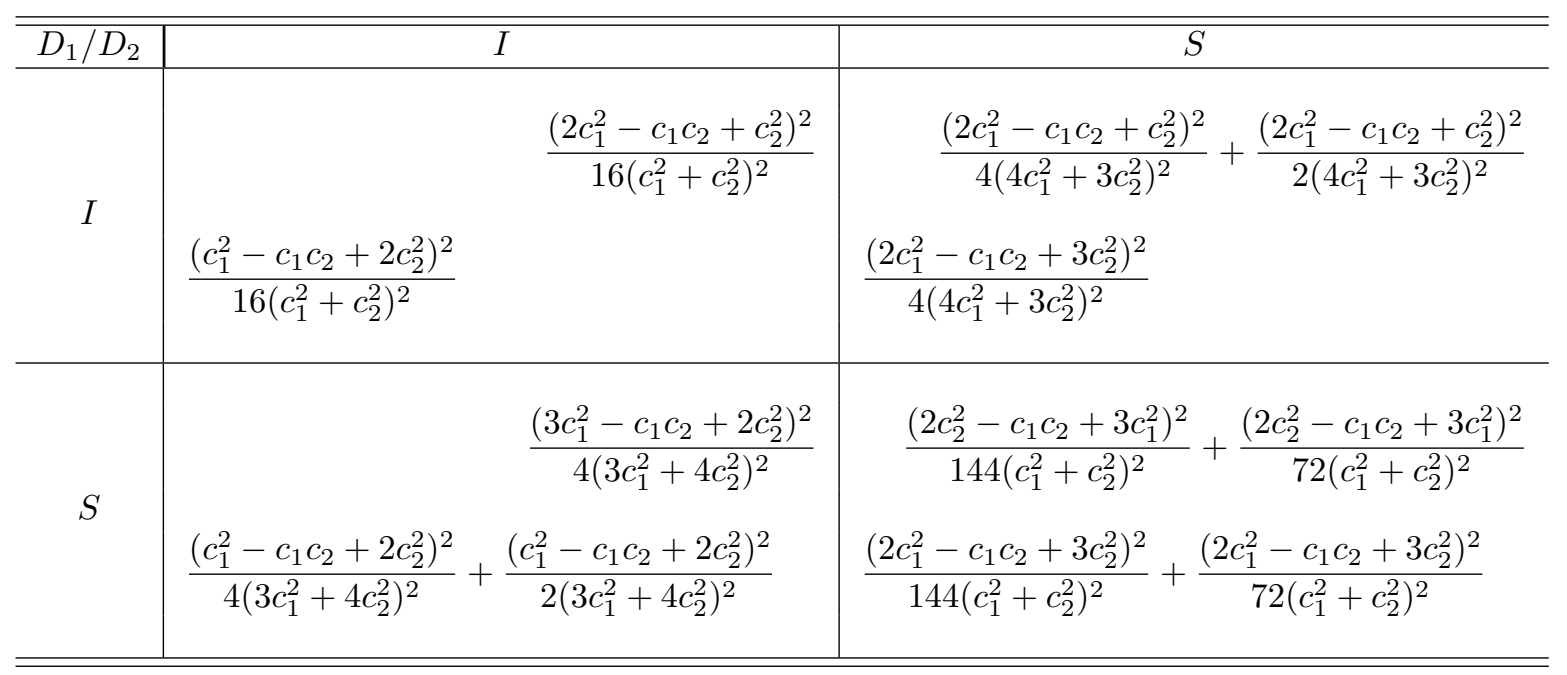

From the payoff matrix, we have the following proposition. 
Proposition $1 D_{1}$ (resp. $D_{2}$ ) vertically separates but $D_{2}$ (resp. $\left.D_{1}\right)$ does not separate vertically in equilibrium if $c_{2} \leq(3 / 4)^{1 / 4} c_{1} \simeq 0.9306 c_{1}$ (resp. $\left.c_{2} \geq(4 / 3)^{1 / 4} c_{1} \simeq 1.0746 c_{1}\right) . D_{1}$ and $D_{2}$ both vertically separate or neither do in equilibrium if $(3 / 4)^{1 / 4} c_{1} \leq c_{2} \leq(4 / 3)^{1 / 4} c_{1}$.

The difference between the efficiencies of their production technologies is large (the absolute value of $\left|c_{2} / c_{1}-1\right|$ is large), and the relatively inefficient firm separates from its production unit $B$.

Basically, vertical separation induces supplier $A$ to lower its wholesale price $w_{A}$. This is because supplier $A$ faces the difficulty of fully exerting monopoly power because of the additional double marginalization problem caused by the separated unit (Cournot (1838) and Sonnenschein (1968)). This diminishes the profit of supplier $A$, and a portion of the monopoly profit of supplier $A$ is transferred to supplier $B$ through competition between the suppliers. Note that because vertical separation enhances the standard double marginalization problem, it diminishes the quantity supplied by the separated downstream firm.

The ratio of the marginal costs $c_{2} / c_{1}$ affects the extent to which vertical separation decreases the wholesale price of supplier $A\left(w_{A}\right)$. We can easily show that $w_{A}^{j k}(j, k \in\{I, S\})$ decreases with $c_{i}$ given that $c_{i} \geq c_{j}(i=1,2, j \neq i)$. This is because the derived demand of supplier $A$ becomes more elastic as the value of $c_{i}$ increases. As a result, a higher value of $c_{i}$ induces supplier $A$ to lower its wholesale price. Now suppose that firm 1 is more efficient without loss of generality $\left(c_{1}<c_{2}\right)$. Vertical separation by firm 1 does not similarly decrease the wholesale price of supplier $A$ because the price level is already low. We can easily check this fact with the following calculus: $\partial w_{A}^{S S} / \partial c_{2}<0, \partial w_{A}^{I S} / \partial c_{2}<0$, and $\partial\left(w_{A}^{I S}-w_{A}^{S S}\right) / \partial c_{2}<0 .{ }^{11}$ This calculus means that the relatively efficient downstream firm does not suffer such an increase in $w_{A}$ caused by its integration decision given that both downstream firms separate from their input units. Therefore, $S S$ does not appear if $c_{2} / c_{1}$ is sufficiently large.

To discuss the incentive of the inefficient downstream firm, we now mention the relations among

\footnotetext{
${ }^{11}$ For any $c_{2} \geq c_{1}$, $\frac{\partial\left(w_{A}^{I S}-w_{A}^{S S}\right)}{\partial c_{2}}=\frac{\partial}{\partial c_{2}}\left(\frac{c_{1}\left(2 c_{1}^{2}-c_{1} c_{2}+3 c_{2}^{2}\right)}{3\left(c_{1}^{2}+c_{2}^{2}\right)\left(4 c_{1}^{2}+3 c_{2}^{2}\right)}\right)=-\frac{c_{1}\left(4 c_{1}^{4}\left(c_{1}+c_{2}\right)+c_{1}^{2} c_{2}^{2}\left(24 c_{2}-7 c_{1}\right)+9 c_{2}^{4}\left(2 c_{2}-c_{1}\right)\right)}{3\left(c_{1}+c_{2}\right)^{2}\left(4 c_{1}+3 c_{2}\right)^{2}}<0$.
} 
$w_{A}, w_{B i}$, and $c_{i}$. We have already mentioned that $w_{A}^{j k}(j, k \in\{I, S\})$ decreases with $c_{i}$ if $c_{i} \geq c_{j}$ $(i=1,2, j \neq i)$. We have also mentioned that a lower $w_{A}$ allows separated suppliers $B i$ to set higher prices $w_{B i}(i=1,2)$, and that the converse also holds. For firm $i$, as the efficiency of firm $j(j \neq i)$ improves, the wholesale price set by $B i$ decreases because of the increase in $w_{A}$. This pricing behavior by $B i$ mitigates the negative effect of the additional double marginalization problem caused by vertical separation. This effect induces the inefficient downstream firm to separate from its input unit. From the discussion, we can conclude that only the inefficient downstream firm $i$ separates from its input unit if $c_{i} / c_{j}$ is large.

\subsection{Case (ii): $Q_{i}=\min \left\{q_{A}, q_{B i} / c_{i}\right\}$}

Given the wholesale prices $w_{A}, w_{B 1}$, and $w_{B 2}$, the maximization problem of $D_{i}$ is:

$$
\max _{Q_{i}}\left(1-Q_{i}-w_{A}-c_{i} w_{B i}\right) Q_{i}
$$

The first-order conditions lead to:

$$
Q_{i}=\frac{1-w_{A}-c_{i} w_{B i}}{2}, \quad \pi_{D_{i}}=\frac{\left(1-w_{A}-c_{i} w_{B i}\right)^{2}}{4} .
$$

As mentioned earlier, the wholesale prices are unilaterally determined by the suppliers. The maximization problems of supplier $A$ and $B_{i}$ are:

$$
\max _{w_{A}} w_{A} \sum_{i=1}^{2} \frac{1-w_{A}-c_{i} w_{B i}}{2}, \max _{w_{B i}} w_{B i} c_{i} \frac{1-w_{A}-c_{i} w_{B i}}{2} .
$$

As in case (i), we have three cases of vertical structure: (1) full separation, (2) partial separation, and (3) no separation. Taking into account that $w_{B i}=0$ if firm $i$ does not separate from $B i$, we derive the first-order condition(s) of the supplier(s). These condition(s) lead to:

$$
\begin{aligned}
& \text { (1) } w_{A}^{S S}=\frac{1}{3}, \quad w_{B i}^{S S}=\frac{1}{3 c_{i}}, \quad \pi_{D i}^{S S}=\frac{1}{36}, \quad \pi_{B i}^{S S}=\frac{1}{18}, \\
& \text { (2a) } w_{A}^{S I}=\frac{3}{7}, \quad w_{B 1}^{S I}=\frac{2}{7 c_{1}}, \quad \pi_{D 1}^{S I}=\frac{1}{49}, \quad \pi_{B 1}^{S I}=\frac{2}{49}, \quad \pi_{D 2}^{S I}=\frac{4}{49}, \\
& \text { (2b) } w_{A}^{I S}=\frac{3}{7}, \quad w_{B 2}^{I S}=\frac{2}{7 c_{2}}, \quad \pi_{D 1}^{I S}=\frac{4}{49}, \quad \pi_{D 2}^{I S}=\frac{1}{49}, \quad \pi_{B 2}^{I S}=\frac{2}{49} \text {, } \\
& \text { (3) } w_{A}^{I I}=\frac{1}{2}, \quad \pi_{D i}^{I I}=\frac{1}{16},
\end{aligned}
$$


where the superscript $S S$ denotes the full-separation setting; the superscript $S I$ (resp. IS) denotes that $D_{1}\left(\right.$ resp. $\left.D_{2}\right)$ separates and $D_{2}\left(r e s p . D_{1}\right)$ integrates; and the superscript $I I$ denotes the no-separation setting.

From the above results, we can make the following payoff matrix related to the first stage decisions of the downstream firms.

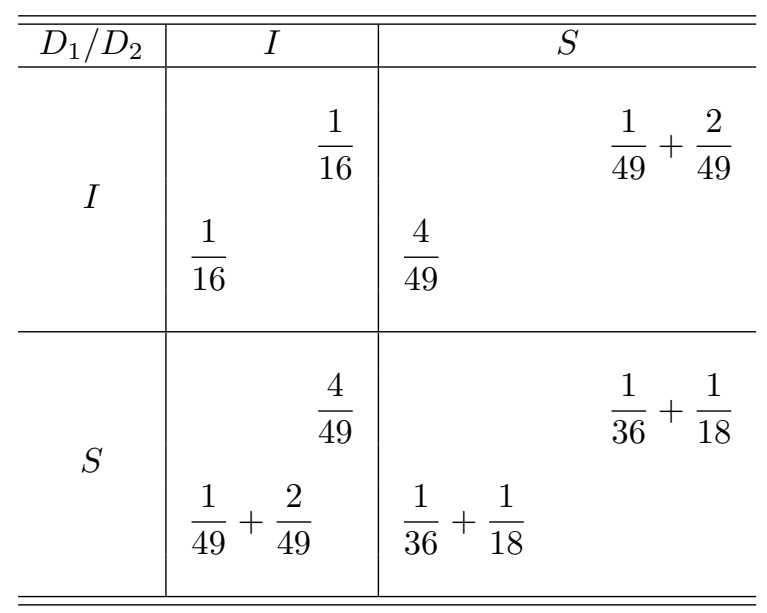

From the payoff matrix, we have the following proposition.

Proposition 2 For any $c_{1}$ and $c_{2}$, both $D_{1}$ and $D_{2}$ separate or neither separates in equilibrium.

Note that in this setting, $c_{i}$ does not affect the profitability of firm $i(i=1,2)$. The strategic interaction between the downstream firms through supplier $A$ exists. The logic behind the proposition is similar to that in the previous model.

\section{Downstream merger}

We now consider the case in which the independent downstream firms merge. We now assume that the efficiencies of the two downstream firms do not change even though they merge (we briefly discuss the case in which the efficiencies are equalized by the merger). At first glance, under the assumption, this merger does not affect the welfare property in the markets because the downstream firms do not compete. As explained below, this intuition is not true, but the merger tends to decrease social welfare. 
The timing of the game is as follows. Given that the downstream firms merge, the merged firm determines its vertical structure. After that, each supplier sets its wholesale price. Finally, the merged firm determines its quantities supplied to the two markets.

We now check the decision of the merged downstream firm on its vertical structure. Anticipating the wholesale price(s) set by the supplier(s) and the quantities it supplies, the merged firm determines its vertical structure. We have already derived the profits under each vertical structure in the previous section. Without loss of generality, we assume that $c_{2} \geq c_{1}$. Using the profits derived in the previous section, we have the following proposition concerning the vertical structure of the merged downstream firm.

Proposition 3 The merged downstream firm separates both input units B1 and B2 if and only if $1 \leq c_{2} / c_{1} \leq 2$; and the merged downstream firm separates only input unit B2 if and only if $c_{2} / c_{1} \geq 2$.

The merged downstream firm tends to separate its input units vertically. The following figure shows the comparison between the two cases. Because vertical separation enhances the problem of double marginalization, the decision of the merged firm is harmful from the viewpoint of social surplus.

[Figure 2 here]

When the downstream firms are independent, each considers only its own profit, even though a vertical separation by a downstream firm harms another downstream firm because of the increase in the wholesale price of supplier $A$. On the other hand, the merged firm internalizes the negative effect of vertical separation. Therefore, the merged firm tends to separate vertically. When the efficiency levels of the merged downstream units are equalized, the merged firm always separates both input units because $c_{2} / c_{1}=1$.

We can interpret the result as follows. A larger downstream firm tends to separate from its production units. In other words, a large firm concentrates its resources on its final product activities, and to do so, it separates from its production units. This result may shed light on the discussion concerning the optimal vertical and horizontal scope of the firm as mentioned in the introduction. 
We now briefly mention the relation between previous research and our paper. Because vertically related industries have recently attracted considerable attention from policymakers, antitrust authorities and economists, several researchers investigate downstream mergers with vertical relations (Horn and Wolinsky (1988), Ziss (1995), Symeonidis (in press) and references therein). Our paper discusses the relation between a downstream merger and the vertical structure in the market. This has not been discussed in previous research. ${ }^{12}$

\section{Price discrimination}

We now consider the case in which supplier $A$ is able to price discriminate. When it does so, the two markets become independent because the strategic interaction through the supplier $A$ disappears. As in the previous section, we calculate two cases concerning production technologies.

\subsection{Case (i): $Q_{i}=\min \left\{q_{A} / c_{i}, q_{B i}\right\}$}

We consider market $i$. Given the wholesale prices $w_{A i}$ and $w_{B i}$, the maximization problem of $D_{i}$ is:

$$
\max _{Q_{i}}\left(1-Q_{i}-c_{i} w_{A i}-w_{B i}\right) Q_{i}
$$

The first-order conditions lead to:

$$
Q_{i}=\frac{1-c_{i} w_{A i}-w_{B i}}{2}, \quad \pi_{D_{i}}=\frac{\left(1-c_{i} w_{A i}-w_{B i}\right)^{2}}{4} .
$$

As mentioned earlier, the wholesale prices are unilaterally determined by the suppliers. The maximization problems of suppliers $A$ and $B_{i}$ are:

$$
\max _{w_{A i}} w_{A i} c_{i} \frac{1-c_{i} w_{A i}-w_{B i}}{2}, \max _{w_{B i}} w_{B i} \frac{1-c_{i} w_{A i}-w_{B i}}{2} .
$$

Here, we have two cases of vertical structure: (1) vertical separation, and (2) no separation. Taking into account that $w_{B i}=0$ if firm $i$ does not separate from $B i$, we derive the first-order condition(s) of

\footnotetext{
12 Ziss (2007) discusses the relation between downstream mergers and the vertical structure within firms. In his model, however, the decision of vertical separation is not discussed.
} 
the supplier(s). These condition(s) lead to:

$$
\begin{aligned}
& \text { (1) } w_{A i}^{S}=\frac{1}{3 c_{i}}, w_{B i}^{S}=\frac{1}{3}, \pi_{D i}^{S}=\frac{1}{36}, \pi_{B i}^{S}=\frac{1}{18}, \\
& \text { (2) } w_{A i}^{I}=\frac{1}{2 c_{i}}, \quad \pi_{D i}^{I}=\frac{1}{16},
\end{aligned}
$$

where the superscript $S$ denotes the vertical separation setting; and the superscript $I$ denotes the no-separation setting. From the above results, we have the following proposition.

Proposition 4 For any $c_{i}, D_{i}$ vertically separates from Bi $(i=1,2)$.

This case is simple. To reduce $w_{A i}$, downstream $D_{i}$ separates from its input unit $B i(i=1,2)$. In this case, the positive effect caused by the decrease in $w_{A i}$ dominates the negative effect caused by the additional double marginalization problem.

We now compare the consumer and the social surplus in the two cases. The consumer surplus and the social surplus in the case where supplier $A$ price discriminates are:

$$
C S_{D}=\frac{1}{36}, \quad S W_{D}=\frac{11}{36}
$$

When supplier $A$ does not price discriminate, if each $D_{i}$ vertically separates from $B i$ (note that this case is the worst among the three vertical structures), the consumer surplus and the social surplus are:

$$
C S_{U}=\frac{13 c_{1}^{2}-10 c_{1} c_{2}+13 c_{2}^{2}}{288\left(c_{1}^{2}+c_{2}^{2}\right)}, \quad S W_{U}=\frac{107 c_{1}^{2}-38 c_{1} c_{2}+107 c_{2}^{2}}{288\left(c_{1}^{2}+c_{2}^{2}\right)} .
$$

The differences between them are:

$$
C S_{U}-C S_{D}=\frac{5\left(c_{1}-c_{2}\right)^{2}}{288\left(c_{1}^{2}+c_{2}^{2}\right)} \geq 0, \quad S W_{U}-S W_{D}=\frac{19\left(c_{1}-c_{2}\right)^{2}}{288\left(c_{1}^{2}+c_{2}^{2}\right)} \geq 0
$$

In this setting, allowing price discrimination is harmful from the viewpoints of consumer and social welfare.

\subsection{Case (ii): $Q_{i}=\min \left\{q_{A}, q_{B i} / c_{i}\right\}$}

Given the wholesale prices $w_{A i}$ and $w_{B i}$, the maximization problem of $D_{i}$ is:

$$
\max _{Q_{i}}\left(1-Q_{i}-w_{A i}-c_{i} w_{B i}\right) Q_{i} .
$$


The first-order conditions lead to:

$$
Q_{i}=\frac{1-w_{A i}-c_{i} w_{B i}}{2}, \quad \pi_{D_{i}}=\frac{\left(1-w_{A i}-c_{i} w_{B i}\right)^{2}}{4}
$$

As mentioned earlier, the wholesale prices are unilaterally determined by the suppliers. The maximization problems of suppliers $A$ and $B_{i}$ are:

$$
\max _{w_{A i}} w_{A i} \frac{1-w_{A i}-c_{i} w_{B i}}{2}, \max _{w_{B i}} w_{B i} c_{i} \frac{1-w_{A i}-c_{i} w_{B i}}{2} .
$$

As in case (i), we have two cases of vertical structure: (1) vertical separation, and (2) no separation. Taking into account that $w_{B i}=0$ if firm $i$ does not separate from $B i$, we derive the first-order condition(s) of the supplier(s). These condition(s) lead to:

$$
\begin{aligned}
& \text { (1) } w_{A i}^{S}=\frac{1}{3}, \quad w_{B i}^{S}=\frac{1}{3 c_{i}}, \pi_{D i}^{S}=\frac{1}{36}, \pi_{B i}^{S}=\frac{1}{18} \\
& \text { (2) } w_{A i}^{I I}=\frac{1}{2}, \pi_{D i}^{I}=\frac{1}{16},
\end{aligned}
$$

where the superscript $S$ denotes the full separation setting; and the superscript $I$ denotes the noseparation setting. From the above results, we have the following proposition.

Proposition 5 For any $c_{i}, D_{i}$ vertically separates from Bi $(i=1,2)$.

When supplier $A$ does not price discriminate, vertical integration can appear in equilibrium. In this model, vertical separation always appears in equilibrium. This never improves social welfare.

\section{Market competition}

To analyze the effect of competition in the downstream market, we assume the differentiated demand is $p_{i}=1-Q_{i}-\gamma Q_{j}$, where $p_{i}$ is the retail price of downstream firm $i, Q_{i}$ (resp. $Q_{j}$ ) is the amount of product sold by downstream firm $i$ (resp. $j$ ), and $\gamma \in[0,1]$ denotes a degree of product differentiation. In the same way as in the previous sections, we calculate two cases. 


\subsection{Case (i): $Q=\min \left\{q_{A} / c_{i}, q_{B i}\right\}$}

Given the wholesale prices $w_{A}, w_{B 1}$, and $w_{B 2}$, the maximization problem of $D_{i}$ is:

$$
\max _{Q_{i}}\left(1-Q_{i}-\gamma Q_{j}-c_{i} w_{A}-w_{B i}\right) Q_{i}
$$

The first-order conditions lead to:

$$
Q_{i}=\frac{2\left(1-c_{i} w_{A}-w_{B i}\right)-\gamma\left(1-c_{j} w_{A}-w_{B j}\right)}{(2-\gamma)(2+\gamma)}, \quad \pi_{D i}=\left[\frac{2\left(1-c_{i} w_{A}-w_{B i}\right)-\gamma\left(1-c_{j} w_{A}-w_{B j}\right)}{(2-\gamma)(2+\gamma)}\right]^{2},
$$

where $i, j=1,2$ and $i \neq j$. As mentioned earlier, the wholesale prices are unilaterally determined by the suppliers. The maximization problems of suppliers $A$ and $B_{i}$ are:

$$
\begin{aligned}
& \max _{w_{A}} w_{A}\left(c_{1} Q_{1}+c_{2} Q_{2}\right) \Rightarrow \max _{w_{A}} w_{A} \sum_{i=1}^{2} c_{i} \frac{2\left(1-c_{i} w_{A}-w_{B i}\right)-\gamma\left(1-c_{j} w_{A}-w_{B j}\right)}{(2-\gamma)(2+\gamma)}, \\
& \max _{w_{B i}} w_{B i} \frac{2\left(1-c_{i} w_{A}-w_{B i}\right)-\gamma\left(1-c_{j} w_{A}-w_{B j}\right)}{(2-\gamma)(2+\gamma)}, \quad(i, j=1,2 \text { and } i \neq j) .
\end{aligned}
$$

Here, we have three cases: (1) full separation, (2) partial separation, and (3) no separation. Taking into account that $w_{B i}=0$ if firm $i$ does not separate from $B i$, we derive the first-order condition(s) of the supplier(s). Solving the first-order conditions, we have the profits of the firms. Using the result, we can ascertain what vertical structure appears in equilibrium as in the previous sections. We have the following proposition $\left(\Delta_{i}(i=1,2,3,4)\right.$ is defined in the Appendix $)$.

Proposition 6 D $D_{1}\left(\right.$ resp. $\left.D_{2}\right)$ vertically separates but $D_{2}$ (resp. $\left.D_{1}\right)$ does not in equilibrium if $\Delta_{2}$ is plus (resp. $\Delta_{4}$ is plus). $D_{1}$ and $D_{2}$ vertically separate or neither of them do in equilibrium if $\Delta_{1}$ is plus, $\Delta_{2}$ is minus, $\Delta_{3}$ is plus, and $\Delta_{4}$ is minus. $D_{1}$ and $D_{2}$ do not vertically separate in equilibrium, otherwise.

This proposition is summarized in Figure 3.

[Figure 3 here]

We have already explained the intuition behind the result that $\gamma=0$. In this setting, we add the competition between the downstream firms. In this competitive environment, a lower procurement 
cost is an advantage for a downstream firm. To lower its procurement cost, downstream firm $i$ has an incentive not to separate from its input unit $B i$. This tendency becomes strong as the degree of competition that is represented by $\gamma$ increases. Therefore, as the value of $\gamma$ increases, the range of $(I, I)$ (none of the downstream firms separates from its input unit) is enlarged.

\subsection{Case (ii): $Q_{i}=\min \left\{q_{A}, q_{B i} / c_{i}\right\}$}

Given the wholesale price $w_{A}, w_{B 1}$, and $w_{B 2}$, the maximization problem of $D_{i}$ is:

$$
\max _{Q_{i}}\left(1-Q_{i}-\gamma Q_{j}-w_{A}-c_{i} w_{B i}\right) Q_{i}
$$

The first-order condition leads to:

$$
Q_{i}=\frac{2\left(1-w_{A}-c_{i} w_{B i}\right)-\gamma\left(1-w_{A}-c_{j} w_{B j}\right)}{(2-\gamma)(2+\gamma)}, \quad \pi_{D i}=\left[\frac{2\left(1-w_{A}-c_{i} w_{B i}\right)-\gamma\left(1-w_{A}-c_{j} w_{B j}\right)}{(2-\gamma)(2+\gamma)}\right]^{2} .
$$

As mentioned earlier, the wholesale prices are unilaterally determined by the suppliers. The maximization problems of suppliers $A$ and $B_{i}$ are:

$$
\begin{aligned}
& \max _{w_{A}} w_{A} \sum_{i=1}^{2} \frac{2\left(1-w_{A}-c_{i} w_{B i}\right)-\gamma\left(1-w_{A}-c_{j} w_{B j}\right)}{(2-\gamma)(2+\gamma)}, \\
& \max _{w_{B i}} w_{B i} c_{i} Q_{i} \Rightarrow \max _{w_{B i}} w_{B i} c_{i} \frac{2\left(1-w_{A}-c_{i} w_{B i}\right)-\gamma\left(1-w_{A}-c_{j} w_{B j}\right)}{(2-\gamma)(2+\gamma)}, \quad(i, j=1,2 \text { and } i \neq j) .
\end{aligned}
$$

Here, we have three cases: (1) full separation, (2) partial separation, and (3) no separation. Considering that $w_{B i}=0$ if firm $i$ does not separate from $B i$, we derive the first-order condition(s) of the $\operatorname{supplier(s).~}$ As in the previous subsection, we derive the equilibrium profits in each vertical structure. From the result, we have the following proposition.

Proposition 7 Both $D_{1}$ and $D_{2}$ separate or neither of them separates in equilibrium if $\gamma \leq 0.3708$. Both $D_{1}$ and $D_{2}$ integrate in equilibrium if $\gamma>0.3708$.

\section{Concluding remarks}

We provide a simple model to investigate decisions of vertical separation. The key feature of this model is that more than one input is required for the final products of the local downstream monopolists. Depending on the cost structure of the downstream firms, their decisions on vertical separation can be both 
strategic complements and strategic substitutes. As a result, one of our models can derive the following three situations concerning the vertical structures of the downstream firms: both downstream firms vertically integrate; no downstream firm vertically integrates when the decisions on vertical integration are strategic complements; and only one downstream firm vertically integrates when the decisions on vertical integration are strategic substitutes. Our model also shows that downstream competition in itself is not essential in decisions of vertical integration/separation. In our model, the two downstream firms are local monopolists and procure their inputs from a common supplier. These features of our model are quite different from those of previous studies.

We have extended the basic model in several directions. First, we consider a downstream merger. When the downstream firms merge, full integration does not appear in equilibrium but rather vertical separation tends to appear. This tendency reduces social welfare. Second, we allow a common supplier to price discriminate. We show that both downstream firms vertically separate when the common supplier price discriminates. As a result, allowing price discrimination reduces social welfare. Third, we investigate the case in which the downstream firms compete. We show that the downstream firms tend to integrate when the degree of product differentiation is lower.

In this paper, we have assumed that the production technology of downstream firms is of the Leontief type. That is, two inputs are perfectly complementary. Although this assumption simplifies the analyses executed here, it may be restrictive. Incorporating other assumptions of the production technology into our basic model is a consideration for future research. We have set the number of downstream firms at two in this paper. When the number of downstream firms is more than two, the strategic interaction among the downstream firms and the common supplier would be more complicated. This is also a significant topic for future research. 


\section{Appendix}

We now discuss the results in Section 6.

Case (i) Solving the optimization problem(s) of the supplier(s), we have the following result (we now set $c=c_{2} / c_{1}$ without loss of generality):

(1)

$$
\begin{aligned}
& w_{A}^{S S}=\frac{\left(c_{1}+c_{2}\right)\left(8-2 \gamma-\gamma^{2}\right)}{2\left(c_{1}^{2}+c_{2}^{2}\right)\left(12-\gamma^{2}\right)-c_{1} c_{2} \gamma(20-\gamma)}, \\
& w_{B i}^{S S}=\frac{(2-\gamma)\left[c_{i}^{2}(4+\gamma)+2 c_{j}^{2}(3+\gamma)-c_{i} c_{j}\left(2+5 \gamma+\gamma^{2}\right)\right]}{2\left(c_{i}^{2}+c_{j}^{2}\right)\left(12-\gamma^{2}\right)-c_{i} c_{j} \gamma\left(20-\gamma^{2}\right)} \\
& \pi_{D 1}^{S S}+\pi_{B 1}^{S S}=\frac{2\left(6-\gamma^{2}\right)\left(4-2 c+6 c^{2}+\gamma-5 c \gamma+2 c^{2} \gamma-c \gamma^{2}\right)^{2}}{(2+\gamma)^{2}\left(24+24 c^{2}-20 c \gamma-2 \gamma^{2}-2 c^{2} \gamma^{2}+c \gamma^{3}\right)^{2}} \\
& \pi_{D 2}^{S S}+\pi_{B 2}^{S S}=\frac{2(6-\gamma)\left(6-2 c+4 c^{2}+2 \gamma-5 c \gamma+c^{2} \gamma-c \gamma^{2}\right)^{2}}{(2+\gamma)^{2}\left(24+24 c^{2}-20 c \gamma-2 \gamma^{2}-2 c^{2} \gamma^{2}+c \gamma^{3}\right)^{2}}
\end{aligned}
$$

$$
\begin{aligned}
& w_{A}^{S I}=\frac{(2-\gamma)\left[2 c_{1}+c_{2}(4+\gamma)\right]}{12 c_{1}^{2}+c_{2}^{2}\left(16-\gamma^{2}\right)-12 c_{1} c_{2} \gamma}, \quad w_{B 1}^{S I}=\frac{(2-\gamma)\left[c_{1} c_{2}(2+3 \gamma)-2 c_{1}^{2}-2 c_{2}^{2}(4+\gamma)\right]}{12 c_{1}^{2}+c_{2}^{2}\left(16-\gamma^{2}\right)-12 c_{1} c_{2} \gamma} \\
& \pi_{D 1}^{S I}+\pi_{B 1}^{S I}=\frac{2\left(2-2 c+4 c^{2}-3 c \gamma+c^{2} \gamma\right)^{2}\left(6-\gamma^{2}\right)}{(2+\gamma)^{2}\left(12+16 c^{2}-12 c \gamma-c^{2} \gamma^{2}\right)^{2}}
\end{aligned}
$$$$
\pi_{D 2}^{S I}=\frac{4\left(6-2 c+4 c^{2}+2 \gamma-5 c \gamma+c^{2} \gamma-c \gamma^{2}\right)^{2}}{(2+\gamma)^{2}\left(12+16 c^{2}-12 c \gamma-c^{2} \gamma^{2}\right)^{2}},
$$

$$
\begin{aligned}
\text { (2b) } \quad w_{A}^{I S} & =\frac{(2-\gamma)\left[2 c_{2}+c_{1}(4+\gamma)\right]}{12 c_{2}^{2}+c_{1}^{2}\left(16-\gamma^{2}\right)-12 c_{1} c_{2} \gamma}, \quad w_{B 2}^{I S}=\frac{(2-\gamma)\left[2 c_{2}^{2}+c_{1}^{2}(4+\gamma)-c_{1} c_{2}(2+3 \gamma)\right]}{12 c_{2}^{2}+c_{1}^{2}\left(16-\gamma^{2}\right)-12 c_{1} c_{2} \gamma}, \\
\pi_{D 1}^{I S} & =\frac{4\left(4-2 c+6 c^{2}+\gamma-5 c \gamma+2 c^{2} \gamma-c \gamma^{2}\right)^{2}}{(2+\gamma)^{2}\left(16+12 c^{2}-12 c \gamma-\gamma^{2}\right)^{2}}, \\
\pi_{D 2}^{I S} & +\pi_{B 2}^{I S}=\frac{2\left(4-2 c+2 c^{2}+\gamma-3 c \gamma\right)^{2}\left(6-\gamma^{2}\right)}{(2+\gamma)^{2}\left(16+12 c^{2}-12 c \gamma-\gamma^{2}\right)^{2}}, \\
(3) \quad w_{A}^{I I} & =\frac{(2-\gamma)\left(c_{1}+c_{2}\right)}{4\left(c_{1}^{2}+c_{2}^{2}-c_{1} c_{2} \gamma\right)}, \\
\pi_{D 1}^{I I} & =\frac{\left(2-2 c+4 c^{2}-3 c \gamma+c^{2} \gamma\right)^{2}}{16(2+\gamma)^{2}\left(1+c^{2}-c \gamma\right)^{2}}, \quad \pi_{D 2}^{I I}=\frac{\left(4-2 c+2 c^{2}+\gamma-3 c \gamma\right)^{2}}{16(2+\gamma)^{2}\left(1+c^{2}-c \gamma\right)^{2}} .
\end{aligned}
$$

From the above result, we can make the following payoff matrix related to the first-stage decisions of the downstream firms. 


\begin{tabular}{|c|c|c|}
\hline$\overline{D_{1} / D_{2}}$ & $\overline{I I}$ & $\bar{S}$ \\
\hline$I$ & $\begin{array}{l}\pi_{D 2}^{I I} \\
\pi_{D 1}^{I I}\end{array}$ & $\begin{array}{l}\pi_{D 2}^{I S}+\pi_{B 2}^{I S} \\
\pi_{D 1}^{I S}\end{array}$ \\
\hline$S$ & $\begin{array}{r}\pi_{D 2}^{S I} \\
\pi_{D 1}^{S I}+\pi_{B 1}^{S I}\end{array}$ & $\begin{array}{c}\pi_{D 2}^{S S}+\pi_{B 2}^{S S} \\
\pi_{D 1}^{S S}+\pi_{B 1}^{S S}\end{array}$ \\
\hline
\end{tabular}

To derive Proposition 6 , we have to check the following four symbols $\Delta_{i}(i=1,2,3,4)$.

$$
\begin{aligned}
& \operatorname{Sign}\left[\left(\pi_{D 1}^{S S}+\pi_{B 1}^{S S}\right)-\pi_{D 1}^{I S}\right]=\operatorname{Sign}\left[384-256 \gamma^{2}+30 \gamma^{4}-\gamma^{6}+c\left(-384 \gamma+272 \gamma^{3}-16 \gamma^{5}\right)\right. \\
& \left.+c^{2}\left(-80 \gamma^{2}-56 \gamma^{4}-2 \gamma^{6}\right)+c^{3}\left(192 \gamma+32 \gamma^{3}+8 \gamma^{5}\right)+c^{4}\left(-288+48 \gamma^{2}-8 \gamma^{4}\right)\right] \equiv \Delta_{1}, \\
& \operatorname{Sign}\left[\left(\pi_{D 1}^{S I}+\pi_{B 1}^{S I}\right)-\pi_{D 1}^{I I}\right]=\operatorname{Sign}\left[48-32 \gamma^{2}+c\left(-96 \gamma+64 \gamma^{3}\right)\right. \\
& \left.+c^{2}\left(8 \gamma^{2}-32 \gamma^{4}\right)+40 c^{3} \gamma^{3}+c^{4}\left(-64-\gamma^{4}\right)\right] \equiv \Delta_{2}, \\
& \operatorname{Sign}\left[\left(\pi_{D 2}^{S S}+\pi_{B 2}^{S S}\right)-\pi_{D 2}^{S I}\right]=\operatorname{Sign}\left[-288+48 \gamma^{2}-8 \gamma^{4}+c\left(192 \gamma+32 \gamma^{3}+8 \gamma^{5}\right)\right. \\
& +c^{2}\left(-80 \gamma^{2}-56 \gamma^{4}-2 \gamma^{6}\right)+c^{3}\left(-384 \gamma+272 \gamma^{3}-16 \gamma^{5}\right) \\
& \left.+c^{4}\left(384-256 \gamma^{2}+30 \gamma^{4}-\gamma^{6}\right)\right] \equiv \Delta_{3},
\end{aligned}
$$

$\operatorname{Sign}\left[\left(\pi_{D 2}^{I S}+\pi_{B 2}^{I S}\right)-\pi_{D 2}^{I I}\right]=\operatorname{Sign}\left[-64-\gamma^{4}+40 c \gamma^{3}\right.$

$$
\left.+c^{2}\left(8 \gamma^{2}-32 \gamma^{4}\right)+c^{3}\left(-96 \gamma+64 \gamma^{3}\right)+c^{4}\left(48-32 \gamma^{2}\right)\right] \equiv \Delta_{4}
$$

Case (ii) Solving the optimization problem(s) of the supplier(s), we have the following result:

(1) $w_{A}^{S S}=\frac{2}{6-\gamma}, w_{B i}^{S S}=\frac{2-\gamma}{c_{i}(6-\gamma)}, \pi_{D i}^{S S}+\pi_{B i}^{S S}=\frac{2(6-\gamma)}{(6-\gamma)^{2}(2+\gamma)^{2}}$,

$(2 a) w_{A}^{S I}=\frac{6+\gamma}{14+\gamma}, w_{B 1}^{S I}=\frac{4-2 \gamma}{c_{1}(14+\gamma)}, \pi_{D 1}^{S I}+\pi_{B 1}^{S I}=\frac{8(6-\gamma)}{(2+\gamma)^{2}(14+\gamma)^{2}}, \pi_{D 2}^{S I}=\frac{4(4+\gamma)}{(2+\gamma)^{2}(14+\gamma)^{2}}$,

$(2 b) w_{A}^{I S}=\frac{6+\gamma}{14+\gamma}, w_{B 2}^{I S}=\frac{4-2 \gamma}{c_{2}(14+\gamma)}, \pi_{D 1}^{I S}=\frac{4(4+\gamma)^{2}}{(2+\gamma)^{2}(14+\gamma)^{2}}, \pi_{D 2}^{I S}+\pi_{B 2}^{I S}=\frac{8\left(6-\gamma^{2}\right)}{(2+\gamma)^{2}(14+\gamma)^{2}}$,

(3) $w_{A}^{I I}=\frac{1}{2}, \pi_{D i}^{I I}=\frac{1}{4(2+\gamma)^{2}}$. 
From the above results, we can make the following payoff matrix related to the first-stage decisions of the downstream firms.

\begin{tabular}{c|c|c}
\hline \hline$D_{1} / D_{2}$ & $I$ & $S$ \\
\hline \multirow{4}{*}{$I$} & $\frac{1}{4(2+\gamma)^{2}}$ & $\frac{8\left(6-\gamma^{2}\right)}{(2+\gamma)^{2}(14+\gamma)^{2}}$ \\
& $\frac{1}{4(2+\gamma)^{2}}$ & $\frac{4(4+\gamma)^{2}}{(2+\gamma)^{2}(14+\gamma)^{2}}$ \\
\hline \multirow{3}{*}{$S$} & $\frac{4(4+\gamma)}{(2+\gamma)^{2}(14+\gamma)^{2}}$ & $\frac{2(6-\gamma)}{(6-\gamma)^{2}(2+\gamma)^{2}}$ \\
& $\frac{8(6-\gamma)}{(2+\gamma)^{2}(14+\gamma)^{2}}$ & $\frac{2(6-\gamma)}{(6-\gamma)^{2}(2+\gamma)^{2}}$ \\
\hline \hline
\end{tabular}

From the payoff matrix, we have Proposition 7. 


\section{References}

Abiru, M., Nahata, B., Raychaudhuri, S., and Waterson, M., 1998. Equilibrium structures in vertical oligopoly. Journal of Economic Behavior and Organization 37, 463-480.

Ahmadjian, C. L. and Lincoln, J. R., 2001, Keiretsu, governance, and learning: case studies in change from the Japanese automotive industry, Organization Science 12, 683-701.

Baldwin, C.Y., and Woodard, C.J., 2007, 'Competition in Modular Clusters', Working Paper, Harvard Business School.

Beelaerts van Blokland, W.W.A., Verhagen, W.J.C., and Santema, S.C., 2008. The effects of coinnovation on the value-time curve: a quantitative study on product level, Journal of Business Market Management 2, 5-24.

Buehler, S. and Schmutzler, A., 2005. Asymmetric vertical integration. Advances in Theoretical Economics 5(1), Art. 1.

Casadesus-Masanell, R., Nalebuff, B., and Yoffie, D., 2007. Competing complements, Working Paper, Harvard Business School.

Chen, Y., 2001. On vertical mergers and their competitive effects, RAND Journal of Economics 32, $667-685$.

Choi, J. P. and Yi, S.-S., 2000. Vertical foreclosure with the choice of input specifications. Rand Journal of Economics 31, 717-743.

Church, J. and Gandal, N., 2000. Systems competition, vertical merger, and foreclosure. Journal of Economics and Management Strategy 9, 25-51.

Cournot, A. 1838, Researches into the Mathematical Principles of the Theory of Wealth, (Macmillan, New York); English translation, N. Bacon, 1897.

DeGraba, P., 1990. Input market price discrimination and the choice of technology, American Economic Review 80, 1246-1253.

Dufeu, I., 2004. Market size and vertical equilibrium in the context of successive Cournot oligopolies. Topics in Theoretical Economics 4(1), Art. 2.

Economides, N. and Salop, S.C., 1992. Competition and integration among complements, and network market structure, Journal of Industrial Economics 40, 105-123.

Elberfeld, W., 2002. Market size and vertical integration: Stigler's hypothesis reconsidered. Journal of Industrial Economics 50, 23-42. 
Gaudet, G. and Long, N.V., 1996. Vertical integration, foreclosure, and profits in the presence of double marginalization. Journal of Economics and Management Strategy 5, 409-32.

Gertner, R. H. and Stillman, R. S., 2001. Vertical integration and internet strategies in the apparel industry. Journal of Industrial Economics 49, 417-440.

Hemmert, M., 1999. 'Intermediate organization' revisited: a framework for the vertical division of labor in manufacturing and the case of the Japanese assembly industries. Industrial and Corporate Change 8, 487-517.

Hummels, D., Rapoport, D., and Yi, K.M., 1998. Vertical specialization and the changing nature of world trade. FRBNY Economic Policy Review 4, 79-99.

Horn, H. and Wolinsky, A., 1988. Bilateral monopolies and incentives for merger. RAND Journal of Economics 19, 408-419.

Inderst, R. and Valletti, T., 2009. Price discrimination in input markets, RAND Journal of Economics 40, 1-19.

Jansen, J., 2003. Coexistence of strategic vertical separation and integration. International Journal of Industrial Organization 21, 699-716.

Laussel, D., 2008. Buying back subcontractors: the strategic limits of backward integration. Journal of Economics and Management Strategy 17, 895-911.

Linnemer, L., 2003. Backward integration by a dominant firm. Journal of Economics and Management Strategy 12, 231-259.

Macher, J.T. and Mowery, D.C., 2004. Vertical specialization and industry structure in high technology industries. Advances in Strategic Management 21, 317-356.

Maruyama, M. and Minamikawa, K., 2009. Vertical integration, bundled discounts and welfare. Information Economics and Policy 21, 62-71.

Matsushima, N., 2004. Technology of upstream firms and equilibrium product differentiation. International Journal of Industrial Organization 22, 1091-1114.

Matsushima, N., 2009. Vertical mergers and product differentiation, Journal of Industrial Economics $57,812-834$.

Matsushima, N. and Mizuno, T. 2009. Vertical separation as a defense against strong suppliers, ISER Discussion Paper No. 755, Osaka University.

Nalebuff, B.J., 2000. Competing against bundles, in Peter J. Hammond and Gareth D. Myles, eds., Incentives, Organization, and Public Economics: Papers in Honour of Sir James Mirrlees, 323-336, (Oxford University Press, Oxford, UK). 
Olin, J.G, Greis, N.P., and Kasarda, J.D., 1999. Knowledge management across multi-tier enterprises: The promise of intelligent software in the auto industry. European Management Journal 17, $335-347$.

Ordover, J., Saloner, G., and Salop, S., 1990. Equilibrium vertical foreclosure. American Economic Review 80, 127-142.

Pepall, L., Richards, D.J., and Norman, G., 2004. Industrial Organization: Contemporary Theory and Practice, Third Edition (South-Western, Ohio).

Rey, P. and Tirole, J., 2007. A primer on foreclosure, in Armstrong, M. and Porter, R.H. (eds.), Handbook of Industrial Organization, Vol. 3 (Elsevier, Amsterdam, The Netherlands).

Salinger, M. A., 1988. Vertical mergers and market foreclosure, Quarterly Journal of Economics 103, $345-356$.

Sonnenschein, H., 1968. The dual of duopoly is complementary monopoly: or, two of Cournot's theories are one, Journal of Political Economy 76, 316-318.

Symeonidis, G., in press. Downstream merger and welfare in a bilateral oligopoly, International Journal of Industrial Organization.

Yoshida, Y., 2000. Third-degree price discrimination in input markets: output and welfare, American Economic Review 90, 240-246.

Ziss, S., 1995. Vertical separation and horizontal mergers, Journal of Industrial Economics 43, 63-75.

Ziss, S., 2007. Hierarchies, intra-firm competition and mergers, International Journal of Industrial Organization 25, 237-260. 


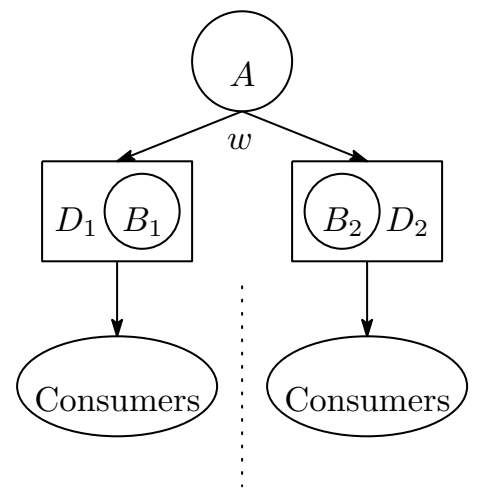

Both firms integrate

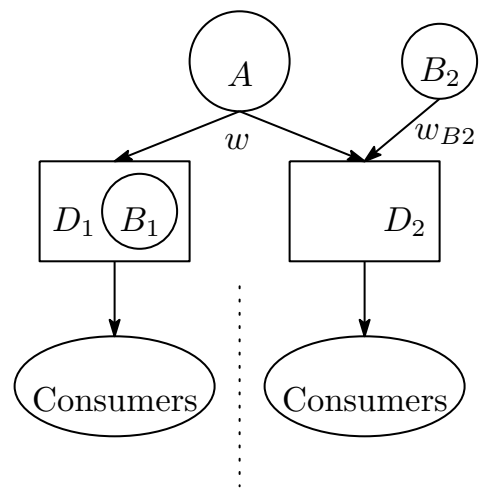

One firm integrates (1)

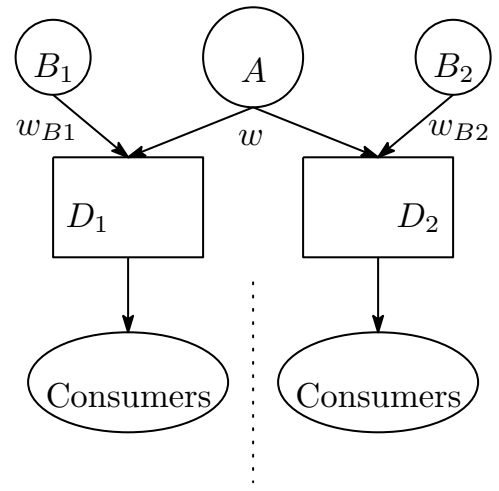

No firm integrates

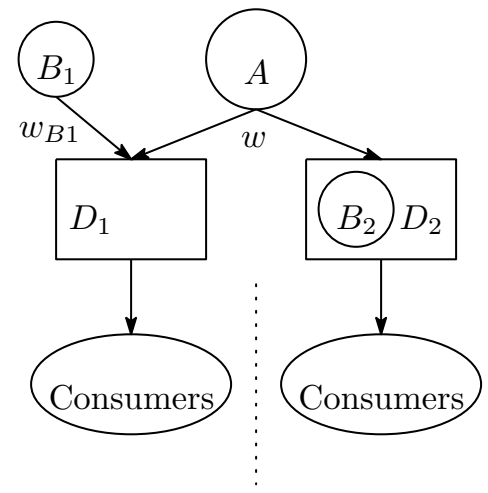

One firm integrates (2)

Figure 1: Four possible vertical structures 


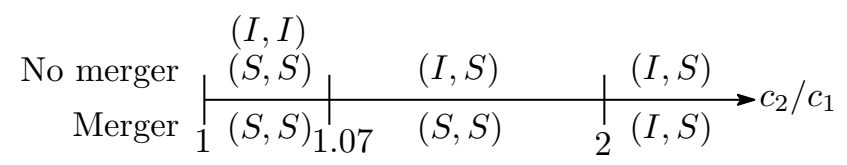

Figure 2: Comparison of the vertical structures in the two cases 


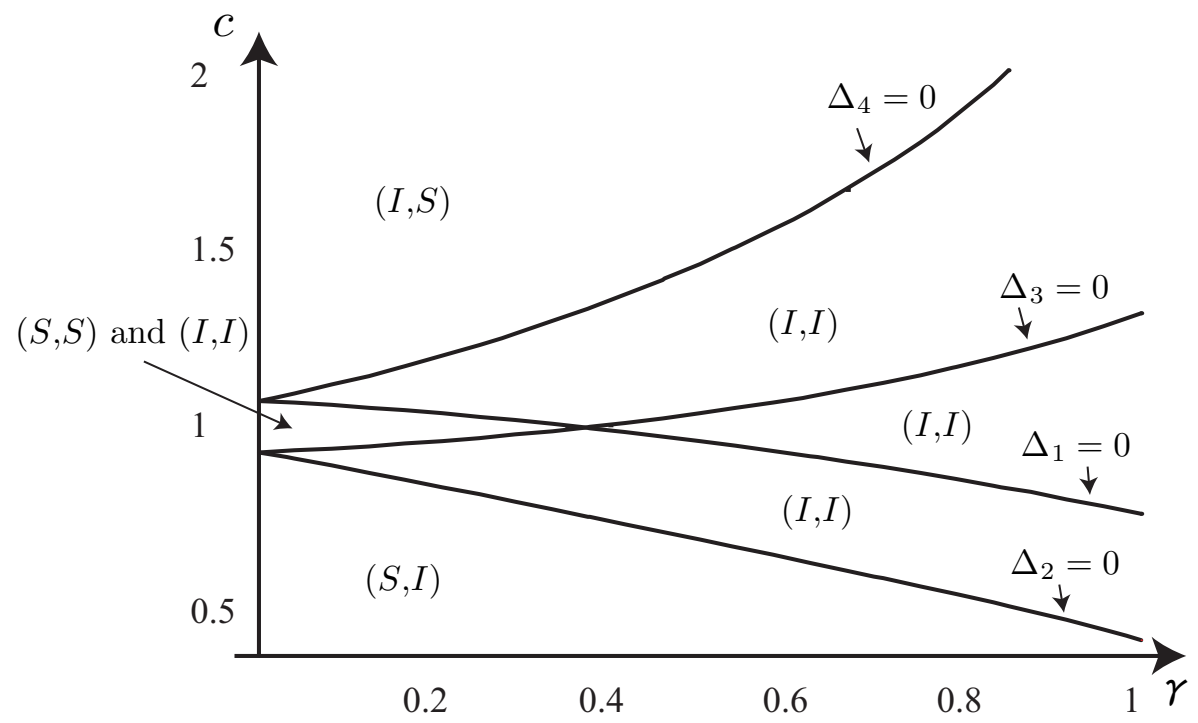

Figure 3: Vertical structure with downstream competition. 